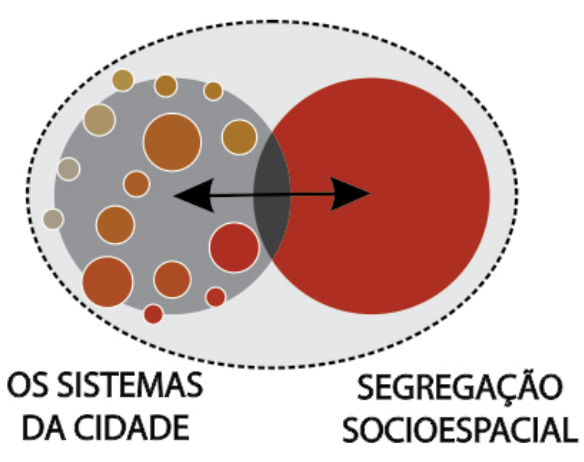

*Arquiteta e Urbanista pela Universidade Estadual de Goiás (2017). Mestrado Acadêmico em formação pela Universidade Federal de Goiás (UFG). Cursando pós-graduação Master em Arquitetura e Lighting pelo Instituto de Pós-Graduação (IPOG). Desenvolve pesquisas relacionadas à mobilidade urbana e metropolitana, estrutura espacial, segregação urbana, espraiamento urbano, planejamento e gestão urbana, Região Metropolitana de Goiânia.

${ }^{* *}$ Arquiteta Urbanista, Mestre e Doutora em Transportes. Desenvolveu pós-doutorado em mobilidade urbana, no Instituto Superior Técnico de Lisboa. Atua como professora/pesquisadora na Universidade Federal de Goiás, no

curso de Arquitetura e Urbanismo e no Programa de PósGraduação Projeto e Cidade. Desenvolve pesquisas relacionadas à mobilidade urbana e metropolitana; planejamento na escala urbana $e$ metropolitana; centralidades e transporte público coletivo.

*** Arquiteto e Urbanista pela Pontifícia Universidade Católica de Goiás (2001), Mestrado no Núcleo de Pós-Graduação em Arquitetura e Urbanismo pela Universidade Federal de Minas Gerais (2008), Doutorado PhD in Architecture at UEL Graduate School - University of East London (2017). É professor adjunto da Universidade $\mathrm{Fe}$ deral de Goiás. Desenvolve pesquisas nos temas: arquitetura, projeto, teorias contemporâneas, urbanismo planejamento urbano.

usjt • arq.urb • número 24 | janeiro - abril de 2019

\title{
O pensamento sistêmico em análises urbanas: uma perspectiva para o problema da segregação socioespacial nas cidades
}

The systemic thinking in urban analyzes: a perspective for the problem ofurban segregation in the cities

Yordana Dias das Neves Naciff*, Erika Cristine Kneib** e Camilo Vladimir de Lima Amaral***

\section{Resumo}

O presente artigo objetiva considerar a utilização da metodologia da abordagem sistêmica em análises urbanas, reconhecendo as cidades enquanto sistemas complexos passíveis de serem ordenados e equacionados na busca por soluções de problemas. Baseada nos conceitos da Teoria Geral dos Sistemas, a abordagem sistêmica é indicada, por vários autores, como um caminho metodológico adequado para integrar disciplinas na solução de um problema real. Para tal, deve-se ter um problema geral complexo que apresente elementos em incessante evolução e que esses possuam uma grande variedade de inter-relações. Visando a aplicação dessa metodologia, o estudo se volta à compreensão da segregação socioespacial enquanto parte integrante do macrossistema complexo das cidades sendo que, normalmente, essa temática é vista enquanto parte excluída desse sistema. Elabora-se uma proposta de pesquisa sistêmica orientada para a temática da segregação urbana. A pesquisa realizada possui natureza descritiva e exploratória a partir da análise de referenciais teóricos. Como resultado da pesquisa, conclui-se que a aplicação metodológica sistêmica em análises urbanas - sobretudo no estudo da segregação socioespacial - contribui de maneira satisfatória para a realização de diagnósticos urbanos. Constata-se também a premissa inicial de que a segregação pode ser analisada enquanto um sistema integrante do macrossistema das cidades.

Palavras-chave: Abordagem sistêmica. Sistemas urbanos. Desigualdade urbana.

\section{Abstract}

The present article aims to consider the use of the methodology of the systemic approach in urban analysis by recognizing cities as complex systems that can be ordered and equated to solve the urban problems. Based on the concepts of the General Theory of Systems, the systemic analysis is indicated by several authors as a suitable methodological way to integrate disciplines in the solution of a real problem. To do so, one must have a complex general problem that presents elements in ceaseless evolution that possess a great variety of interrelationships. Aiming at the application of this methodology, the study turns to the comprehension of the socio-spatial segregation as an integral part of the complex macrosystem of the cities - once this theme is seen as part excluded from this system. A systemic research proposal is developed related to the issue of urban segregation. The research has a descriptive and exploratory nature based on the analysis of theoretical references. By the research it is possible to conclude that the systemic methodological application in urban analyzes - especially in the study of socio-spatial segregation - contributes in a satisfactory way to the accomplishment of urban diagnostics. It was also possible to prove the premise that the segregation can be analyzed as a system that belongs to the macrosystem of cities.

Keywords: Participatory design; Seattle; Taipei; multiethnic communities; landscape design. 


\section{Introdução}

Ante aos vários desafios das cidades contemporâneas, a segmentação territorial e a desigualdade social alcançam uma escala de alto impacto urbano e social. Villaça (2001) aponta a segregação socioespacial como um dos processos mais marcantes das metrópoles brasileiras e como um campo essencial para o entendimento da estrutura espacial intraurbana. Com isso, a segregação se torna, ao mesmo tempo, um problema parcial a ser solucionado e uma parte integrante do sistema das cidades.

As cidades, em incessante evolução, transformam a configuração dos seus espaços urbanos e sociais a todo momento. É um objeto de estudo interdisciplinar, "a maior, mais contraditória e mais complexa estrutura feita pelo homem" (FERREIRA, 2011). Estudar as cidades, consiste, portanto, em compreender que esse objeto das ciências em geral demanda alta complexidade de interpretação.
Diante aos problemas urbanos tem-se, na maioria das vezes, uma percepção da cidade de maneira não abrangente e, sim, fragmentada (OJIMA, 2007; ROMANELLI e ABIKO, 2011; GENTIL et al, 2016). Essa perspectiva parcial desconsidera que, por mais que as cidades apresentem uma série de problemas isolados, eles juntos se combinam em problemas maiores, passíveis de serem solucionados mediante uma abordagem integral, uma visão total desse sistema.

Eis, portanto, que o pensamento sistêmico entra em cena. Emergindo enquanto um novo movimento científico, na metade do século XX, a Teoria Geral dos Sistemas apresentou uma variedade de abordagens e aplicações para lidar com a complexidade e transformações nas mais variadas áreas do conhecimento (KASPER, 2000).

Segundo Kasper (2000), em contradição ao pensamento analítico tradicional que focaliza na análise das partes, o pensamento sistêmico direcio- 
na ao entendimento da existência de um "todo" formado por padrões organizados de interação entre os seus elementos. Sob essa perspectiva, trazer o pensamento sistêmico para o urbanismo, ou seja, assumir as cidades enquanto sistemas complexos, oferece uma possibilidade de abordagem integral do espaço urbano.

Moysés (2005, p. 26) afirma que, a partir dessa forma de análise, se torna possível dar maior visibilidade à cidade real, uma vez que "o município não é um bloco monolítico, mas um todo multifacetado". Apesar de tal afirmação, têm-se, quase sempre, a segregação urbana localizada em um cenário de exclusão do sistema das cidades. Visto que a origem do termo conduz à percepção de uma separação espacial de grupos sociais nas cidades, a segregação é tratada - inclusive na política pública - enquanto uma polarização secundária em relação ao polo central que é a grande cidade (SANTOS, 2008).

Com isso, a pesquisa busca ressaltar uma outra perspectiva para essa temática. A proposta é evidenciar que segregação urbana é um problema que só se justifica ao se reencontrar no "todo" que é a cidade. Há, portanto, a necessidade de ser analisada não somente do ponto de vista da exclusão ou da fragmentação espacial, mas também na sua relação intrínseca com o sistema das cidades - em uma abordagem do tipo sistêmica. Considerando a problemática levantada, a justificativa do trabalho se vincula à necessidade de desenvolvimento de novas soluções aos problemas urbanos existentes - sobretudo em relação ao problema da segregação urbana - buscando uma contribuição teórica acerca da metodologia sistêmica enquanto alternativa ao pensamento analítico tradicional no urbanismo.

Objetiva-se neste trabalho compreender a segregação enquanto um sistema presente no macrossistema das cidades. Visando, portanto, a utilização da abordagem sistêmica em análises urbanas e a compreensão da segregação socioespacial enquanto parte integrante do sistema de interconexões das cidades - um pequeno passo para a pesquisa dos sistemas urbanos. Para tal, a metodologia utilizada nessa pesquisa se amparou em pesquisas bibliográficas para a construção de um referencial teórico com enfoques e percepções variadas acerca do assunto, seguida de uma análise a partir de quadros e infográficos para sistematização.

A discussão presente nesse artigo reforça os princípios abordados por diversos autores acerca da Teoria Geral dos Sistemas e estabelece possibilidades de conexões entre a abordagem sistêmica, as cidades e a segregação socioespacial. 


\section{A Teoria Geral dos Sistemas}

Estabelecida nos anos 1940 pelo biólogo húngaro Ludwig Von Bertalanffy, a Teoria Geral dos Sistemas (TGS) reconhece a existência de um "todo organizado" formado por elementos interconectados que possuem um objetivo comum (MACEDO et al, 2008). Trata-se da compreensão dos fenômenos de forma mais abrangente dentro de um contexto maior.

Macedo et al (2008) discorre sobre as origens das abordagens de sistemas com o biólogo Bertalanffy que iniciou, em 1920, estudos sobre o uso de sistemas nos campos da biologia. A partir de 1950, sua ideia ampliou e já visava "substituir os fundamentos reducionistas da ciência pela visão mais ampla da realidade" em todos os campos disciplinares (NETO e LEITE, 2010, p.5). Essa visão de Bertalanffy declara que todos os sistemas são semelhantes, sejam eles físicos, biológicos ou sociais.

Kasper (2000) aponta que, juntamente com a contribuição teórica deBertalanffy, a consolidação prática do termo "sistema" foi notória com o avanço tecnológico a partir da Segunda Guerra Mundial. As máquinas industriais passaram a ser utilizadas em conjunto, isto é, ao invés de máquinas isoladas, passou a haver uma máquina que controlava todas as outras: um sistema de automatização (KASPER, 2000). Isso afirma, portanto, que o impulso das transformações sociais que es- tavam ocorrendo no mundo, associadas com os avanços tecnológicos, demandou uma outra percepção de análise dos fatos que fosse diferente do pensamento tradicional analítico.

Oliveira e Portela (2006, p.168) definem a TGS enquanto uma teoria intuitiva e simples. Para as autoras, cada sistema "é composto por subsistemas ou componentes e está integrado num macrossistema", sendo o "todo" superior à soma das partes que o compõe. Um sistema é alterado conforme a dinâmica do meio, sofrendo alterações constantes e, podendo ou não, alcançar o equilíbrio.

Num sistema, a entropia (desordem) pode ser reduzida e mesmo transformada em entropia negativa, quando a ordem aumenta dentro do sistema. Cada sistema aberto pode encontrar estados de equilíbrio com o respectivo ambiente. Esse equilíbrio pode ainda resultar de um estado de máxima entropia, que significa um equilíbrio dinâmico. Cada sistema está permanentemente recebendo os resultados das suas ações. Chama-se a isso retroação ou feedback, e pode ser positivo - quando está no "caminho certo" - ou negativo, quando se desvia da organização ou do equilíbrio dinâmico (OLIVEIRA e PORTELA, 2006, p. 168-169).

A retroação ou feedback do sistema, conforme Neto e Leite (2010, p. 6), consiste em um fenômeno que altera a dinâmica do sistema a fim de manter o "controle do sistema no sentido de atingir seus objetivos". Kasper (2000) complementa que o princípio básico de organização de entidades complexas é baseado na combinação de intera- 


\begin{tabular}{|c|c|}
\hline \multicolumn{2}{|r|}{ Princípios Básicos da Abordagem Sistêmica } \\
\hline 1 & Um sistema é maior que a soma de suas partes; \\
\hline 2 & $\begin{array}{l}\text { A investigação de qualquer parte do sistema deve ser sempre realizada em relação ao } \\
\text { todo; }\end{array}$ \\
\hline 3 & $\begin{array}{l}\text { Embora cada subsistema possa ser visto como uma unidade autocontida, ele faz parte } \\
\text { de uma ordem maior e mais ampla, que o contém; }\end{array}$ \\
\hline 4 & $\begin{array}{l}\text { O objetivo central de um sistema pode ser identificado pelo fato de que o cumprimento } \\
\text { de outros objetivos pode ser sacrificado em nome de obter-se a realização do objetivo } \\
\text { central; }\end{array}$ \\
\hline 5 & Um sistema aberto e seu ambiente estão em permanente inter-relação; \\
\hline 6 & $\begin{array}{l}\text { Um sistema altamente complexo pode ser melhor entendido se for dividido em } \\
\text { subsistemas menores, que possam ser mais facilmente analisados e-posteriormente } \\
\text { - recombinados no todo; }\end{array}$ \\
\hline 7 & $\begin{array}{l}\text { Um sistema compõe-se de uma rede de elementos inter-relacionados: uma mudança } \\
\text { em um dos elementos provocará mudanças nos demais ou na totalidade do sistema; }\end{array}$ \\
\hline 8 & $\begin{array}{l}\text { Os sistemas, para serem viáveis a longo prazo, devem perseguir com clareza seus } \\
\text { objetivos, serem governados por retroalimentação e apresentar a capacidade de } \\
\text { adaptar-se a mudanças ambientais. }\end{array}$ \\
\hline
\end{tabular}

Figura 1. Princípios Básicos da Abordagem Sistêmica. Fonte: Macedo et al (2008), adaptado pelos autores. ções sensitivas e ativas em laços de retroação, o que foi definido enquanto "complexidade organizada" nos primeiros anos do movimento sistêmico.

A partir dessa caracterização denominada "complexidade organizada", pode-se observar que, segundo Uhlmann (2002), há várias outras classificações possíveis para os sistemas:

- Complexos organizados: o todo é maior que a soma das partes;

- Complexos desorganizados: o todo é menos que a soma das partes;

- Complexos neutros: a organização e desorganização se anulam mutuamente;

- Concretos ou abstratos: em relação à ordenação das ideias;

- Naturais ou artificiais: com a presença ou não da ação humana;

- Abertos ou fechados: em relação às trocas de informações com o meio;

- Estáticos ou dinâmicos: se podem ser alterados pelo ambiente.

Conforme Macedo et al (2008), todos os campos do conhecimento humano possuem sistemas e, quando abordados segundo a TGS, tendem a obter resultados muito satisfatórios - principalmente quando possuem um caráter multidisciplinar. Mediante tal afirmação, os autores sistematizam os princípios básicos da abordagem sistêmica, conforme (Figura 1). 
Oliveira (2006) ressalta ainda que há quatro propriedades fundamentais da teoria dos sistemas, as quais são:

- Interação: Trata-se da ação recíproca que modifica o comportamento ou a natureza dos elementos componentes de um sistema. Pressupõe uma ação de via dupla, de troca entre elementos;

- Totalidade: Pressupõe-se que um sistema não é igual à soma das suas partes, de forma cartesiana. O todo é mais complexo, pois apresenta qualidades que não existem, individualmente, nas partes. Pressupõem a noção de hierarquia nos sistemas;

- Organização: A organização se caracteriza pelo seu grau de estabilidade, pelo arranjo de relações entre os componentes, produzindo nova unidade, possuidora de propriedades não contidas nos componentes;

- Complexidade: Está diretamente ligada ao número de elementos e ao número de tipos de relações que ligam, entre si, os elementos do sistema. Caracteriza a originalidade do sistema e mede a riqueza de informações nele contida.

Por outro lado, é importante ressaltar que há perspectivas antônimas ao assunto. O documentário All Watched Over by Machines of Loving Grace (2011), dirigido por Adam Curtis, apresenta um outro ponto de vista sobre a teoria dos sistemas. Para o diretor, essa teoria vista como um método de análise universal é, na verdade, um equívoco.
Curtis demonstra que, por exemplo, aplicar a teoria dos sistemas em um ambiente natural pode levar a grandes conflitos. Ao associar as leis da ecologia com os princípios cibernéticos e políticos, revela-se que a natureza não tende ao equilíbrio e que é, de fato, um estado constante de mudanças e imprevisibilidades. Essa afirmação rompeu com a maior premissa da ecologia.

Contudo, o diretor sustenta a ideia de o mundo ser, realmente, visto enquanto um sistema dinâmico, mas ressalta o cuidado para não se preservar o sistema de forma estacionária e salienta a impossibilidade de se estabelecer uma ordem mundial igualitária. Por certo, o modelo de pensamento auto organizado e equilibrado tem suas limitações. É importante avaliar em qual disciplina objetiva-se aplicar a abordagem sistêmica para não se suceder em enganos.

Percebendo, portanto, a Teoria Geral dos Sistemas sob as variadas perspectivas aqui abordadas, compreende-se enquanto "sistema" um complexo amplo formado por um conjunto de elementos em interação entre si e em intercâmbio constante com o meio.

O desenvolvimento de análises urbanas na metodologia da TGS busca a imposição de uma lógica na realidade. Para esse estudo, considera-se as cidades enquanto um sistema complexo de instabilidade caótica e não igualitária. Trata-se, portanto de um sistema complexo aberto e di- 
nâmico em constante mutação pelas trocas de informação com o ambiente, ressaltando ainda que, no caso das cidades, a complexidade se torna maior, uma vez que "o fator humano introduz uma segunda dimensão de complexidade" (KASPER, 2000, p. 4).

\section{Cidades, sistemas e interação}

Por muito tempo a sociedade se baseou em uma visão cartesiana e mecanicista da cidade e do mundo. Se tratava de uma percepção monolítica que só veio a ser alterada a partir do fenômeno da urbanização extensiva das cidades e com a difusão - cada vez mais agressiva - do ideário capitalista (OLIVEIRA, 2006). Como consequência, houve um embate entre a sociedade, o ambiente e sua condição urbana que culminou em uma "necessidade de se repensar modelos, hábitos, padrões, comportamentos" (SILVA, 2011, p. 3).

Nessa conjuntura, o pensamento das cidades ganhou um outro olhar: uma moderna concepção do que seria o mundo real. Considerou-se, a partir de então, as cidades enquanto um caos e vida como um produto dos processos físicos, "[...] o mundo vivo havia aparecido como um produto do acaso resultante das mutações diárias da sobrevivência na seleção natural”' (OLIVEIRA, 2006, P. 171).

Ver o mundo enquanto um caos demandou outra visão para a solução de seus problemas que fosse diferente daquela cartesiana e mecanicista. Eis, portanto, que parecia coerente considerar as teorias sistêmicas de Bertalanffy nas análises das ciências sociais, sobretudo, nas análises das cidades.

Segundo Oliveira (2006), foram realizados vários estudos empíricos sobre as cidades que constataram a existência de relações complexas entre os diversos elementos urbanos. Confirmou-se assim, um dos princípios fundamentais da teoria dos sistemas aplicado às cidades: a complexidade. A partir disso, analisar as cidades enquanto um sistema se tornou possível e, de certa forma, cada vez mais simples de se realizar, à medida em que se identificavam os subsistemas da cidade e compreendiam suas interações.

Neto e Leite (2010) afirmam que, para enquadrar um tema na Teoria Geral dos Sistemas, torna-se necessário que o mesmo seja definido por "complexo" segundos as características abaixo:

- O sistema deve ser composto por uma variedade de elementos que apresentem funções e comportamentos múltiplos.

- Os elementos desse sistema estão em incessante evolução, são influenciados por fatos imprevisíveis e as informações sobre esses elementos não pode ser conhecida de maneira total.

- Os múltiplos elementos possuem uma grande variedade de inter-relações. 
As cidades são, de fato, um problema complexo e possuem todas as características anteriormente descritas. Oliveira (2006, p.174) aponta que o sistema urbano é "suficientemente flexível para escapar ao determinismo" e que depende de trocas de energia constantes com o meio para manter seu equilíbrio. Isso afetaria todo um sistema que fosse fechado e rígido, por isso as cidades não poderiam ser definidas dessa forma.

Contudo, as cidades são sistemas complexos abertos e dinâmicos em constante mutação pelas trocas de informação com o ambiente. Essas trocas e interações configuram uma inter-relação entre o sistema e seus subsistemas, ou seja, entre a cidade e seus campos de análise (estrutura espacial, ambiental, infraestrutura e uso do solo, saúde e segurança, mobilidade e acessibilidade, segregação urbana, qualidade de vida, dentre outros).

Logo, utilizar a abordagem sistêmica nos estudos urbanos significa perfazer uma visão ampla do tema uma vez que, segundo Silva (2011, p. 10), "não basta descrever as diversas partes que o compõe, mas que também é necessário investigar as interações entre essas partes e as interações entre o fenômeno e o universo que o rodeia".

Com isso, uma abordagem integrada entre cidades, sistemas e interações se mostra coerente e se apresenta enquanto uma ferramenta plausível de ser utilizada. É nessa perspectiva em que se configura o objetivo geral da pesquisa. Tem-se, a seguir, uma interpretação da Teoria Geral dos Sistemas através das conexões entre a abordagem sistêmica e a segregação socioespacial dentro do macrossistema das cidades.

\section{Abordagem sistêmica e a segregação so- cioespacial}

Neste trabalho considera-se a segregação socioespacial como objeto de pesquisa, a abordagem sistêmica como processo de análise e a cidade como o macrossistema em que a segregação se insere. Tal é a configuração estrutural e temática que propõe a discussão central dessa pesquisa.

Para compreender a análise proposta, será apresentado, a priori, um breve panorama do termo "segregação" - utilizado massivamente nesta pesquisa - almejando alcançar uma percepção mais direcionada do objeto deste estudo.

Segundo Silva (2007), para entender a segregação urbana, é necessário, a princípio, compreender os processos de urbanização das cidades brasileiras. A autora afirma que foi a partir de 1950, com modernizações tecnológicas e com a industrialização das cidades, que o processo de urbanização foi intensificado pelas migrações internas, direcionando massivamente a população dos campos para as cidades. 


\begin{tabular}{|c|c|}
\hline \multicolumn{2}{|r|}{ Fatores em relação direta com a segregação socioespacial } \\
\hline Política Pública & $\begin{array}{l}\text { "[...] nenhum padrão urbanístico poderia ser adotado sem a participação do } \\
\text { Estado, seja ele segregador ou não. Isto se dá através de leis que garantam o } \\
\text { direito à propriedade privada contra invasões e que usem o aparato coercitivo } \\
\text { (polícia, tribunais etc) do Estado para controlá-las". (NEGRI, 2008) }\end{array}$ \\
\hline Direito à Cidade & $\begin{array}{l}\text { "Tal processo de segregação está intimamente ligado ao 'direito à cidade' e ao } \\
\text { poder público como articulador do espaço urbano. O subúrbio e as favelas, } \\
\text { enfim, a periferia pobre, não tem direito à cidade, não só por conta do preço do } \\
\text { solo e especulação imobiliária, impedindo o acesso à cidade formal, como } \\
\text { também devido à sua locomoção (transportes) [...]". (CEZARIO e CAETANO, } \\
\text { 2010) }\end{array}$ \\
\hline $\begin{array}{l}\text { Especulação } \\
\text { Imobiliária }\end{array}$ & $\begin{array}{l}\text { "O mercado imobiliário é elemento primordial para o entendimento da } \\
\text { segregação socioespacial. Diversos trabalhos apresentam essa perspectiva } \\
\text { como elemento central nos processos de exclusão socioespacial. Dessa forma, } \\
\text { o espaço em que determinado indivíduo vai se localizar deve concordar ao } \\
\text { máximo com aquele socialmente aceito como sendo seu lugar de ocupação, o } \\
\text { que leva os pobres para as periferias e os ricos para as áreas valorizadas". } \\
\text { (CANATTIERI, 2015, p.6) }\end{array}$ \\
\hline $\begin{array}{l}\text { Estrutura } \\
\text { Econômica }\end{array}$ & $\begin{array}{l}\text { "A cidade capitalista é desigual e o processo de urbanização tem produzido e } \\
\text { aprofundado as desigualdades e injustiças da cidade, já que é realizado para } \\
\text { atender os interesses da acumulação de capital. [...] No capitalismo, a } \\
\text { segregação se organiza a partir de uma } \\
\text { estrutura de classes e, o modo de produção, organizado a partir dessa } \\
\text { separação, se materializa no espaço das cidades.". (CANATTIERI, 2015, p.3- } \\
\text { 5) }\end{array}$ \\
\hline Estrutura Territorial & $\begin{array}{l}\text { "A identificação de um subúrbio, qualquer que ele seja independentemente do } \\
\text { tempo ou do lugar, implica uma ideia de fragmentação do espaço urbano. A } \\
\text { cidade compacta, de limites precisos, estilhaça-se num conjunto de fragmentos } \\
\text { distintos onde os efeitos de coesão, de continuidade e de legibilidade } \\
\text { urbanística, dão lugar a formações territoriais urbanas complexas, } \\
\text { territorialmente descontinuas e ocupando territórios cada vez mais alargados". } \\
\text { (DOMINGUES, 1994/5, p.6) }\end{array}$ \\
\hline $\begin{array}{l}\text { Acessibilidade / } \\
\text { Mobilidade Urbana }\end{array}$ & $\begin{array}{l}\text { "[Milton Santos, 1987] chamava atenção para o direito que o cidadão deveria } \\
\text { ter à mobilidade espacial e ao acesso a serviços públicos, questionando assim } \\
\text { a fixação da pobreza em determinados espaços" (MAIOLINO e MANCEBO, } \\
\text { 2005, p.16) } \\
\text { "O direito à circulação e à mobilidade é uma das demandas que aparecem de } \\
\text { forma incisiva [...], tendo em vista que esse direito se relaciona diretamente com } \\
\text { o exercicio da cidadania plena, principalmente com o acesso à educação, ao } \\
\text { trabalho, à cultura e ao lazer". (DUARTE, 2012, p. 136) }\end{array}$ \\
\hline Empregabilidade & $\begin{array}{l}\text { "Nos loteamentos periféricos do entorno destinados às classes de menor poder } \\
\text { aquisitivo, a distância e o deslocamento, principalmente em função dos locais } \\
\text { de trabalho, apresentam-se como um grande obstáculo às oportunidades de } \\
\text { emprego, da mesma forma que apresentam problemas relativos à carência de } \\
\text { meios de consumo coletivo". (CEZARIO e CAETANO, 2010) }\end{array}$ \\
\hline Cidadania & $\begin{array}{l}\text { "A dinâmica urbana é sempre mais rápida do que os ajustamentos político- } \\
\text { administrativos e institucionais. Isto significa que, na ausência de organismos } \\
\text { locais com um minimo de competências que favoreçam um clima de } \\
\text { democracia participativa, o subúrbio e os suburbanos sejam largamente } \\
\text { afectados por uma incapacidade ou por uma limitação no exercício da sua } \\
\text { cidadania". (DOMINGUES, 1994/5, p.9) }\end{array}$ \\
\hline
\end{tabular}

Dessa forma, as cidades cresceram extensivamente e, aliadas com a especulação imobiliária, culminaram na "distribuição espacial profundamente desigual em termos de moradia, renda, oferta de serviços e de infraestrutura urbana, e segurança ambiental" (ROMANELLI e ABIKO, 2011, p.3). Ou seja, de maneira desordenada, formaram-se aglomerados populacionais localizados nos limites territoriais urbanos, marcados pela precariedade e pela escassez de assistência e de recursos.

Contudo, a origem do termo "segregação" conduz à percepção de uma separação de grupos sociais nas cidades por motivos diversos, frequentemente relacionada com alguns outros fatores como: a estrutura territorial, empregabilidade, mobilidade urbana, direito à cidade, acessibilidade urbana, cidadania, estrutura econômica, políticas públicas (GROSTEIN, 2001; ROMANELLI e ABIKO, 2011; SABOYA, 2009; VILLAÇA, 2001). Dada a complexidade e abrangência do tema, cabe destacar que esses fatores possuem relação direta com a segregação socioespacial (Figura 2), no entanto, se configuram enquanto exemplos iniciais para aplicação da teoria, dentre um grande espectro de elementos que podem ser complementados por outras pesquisas.

Assim, através dessa conceituação e a partir das teorias anteriormente apresentadas, se torna possível traçar uma outra perspectiva para a temática da segregação urbana, baseando-se nos princípios da abordagem sistêmica. A proposta, como
Figura 2. Fatores em relação direta com a segregação socioespacial. Fonte: Elaborado pelos autores. 
já descrito, é evidenciar que segregação urbana é um problema que só se justifica ao se reencontrar no "todo" que é a cidade, estabelecendo uma relação intrínseca com o sistema das cidades.

Essa interpretação se difere da perspectiva clássica em que a segregação se apresenta enquanto um sistema isolado, porém relacionado ao grande sistema da cidade (CANETTIERI, 2016). A perspectiva proposta nessa pesquisa se refere, na verdade, na existência de um sistema global: a cidade enquanto um macrossistema composto por vários outros sistemas, dentre os quais a segregação seria um deles (Figura 3).
Conforme abordado anteriormente, a cidade contemporânea é conformada enquanto um sistema composto de vários problemas complexos a serem solucionados, sobretudo a problemática da segregação urbana. No cenário formado principalmente pelo fenômeno da urbanização extensiva, tudo se fragmenta nas cidades e a segregação socioespacial se torna o espelho dessa conjuntura social repartida (SILVA, 2011).

É possível notar que o padrão de urbanização atual - internacional e nacional - conforma regiões metropolitanas descontinuadas e heterogêneas, tanto na morfologia espacial quanto nas caracte-

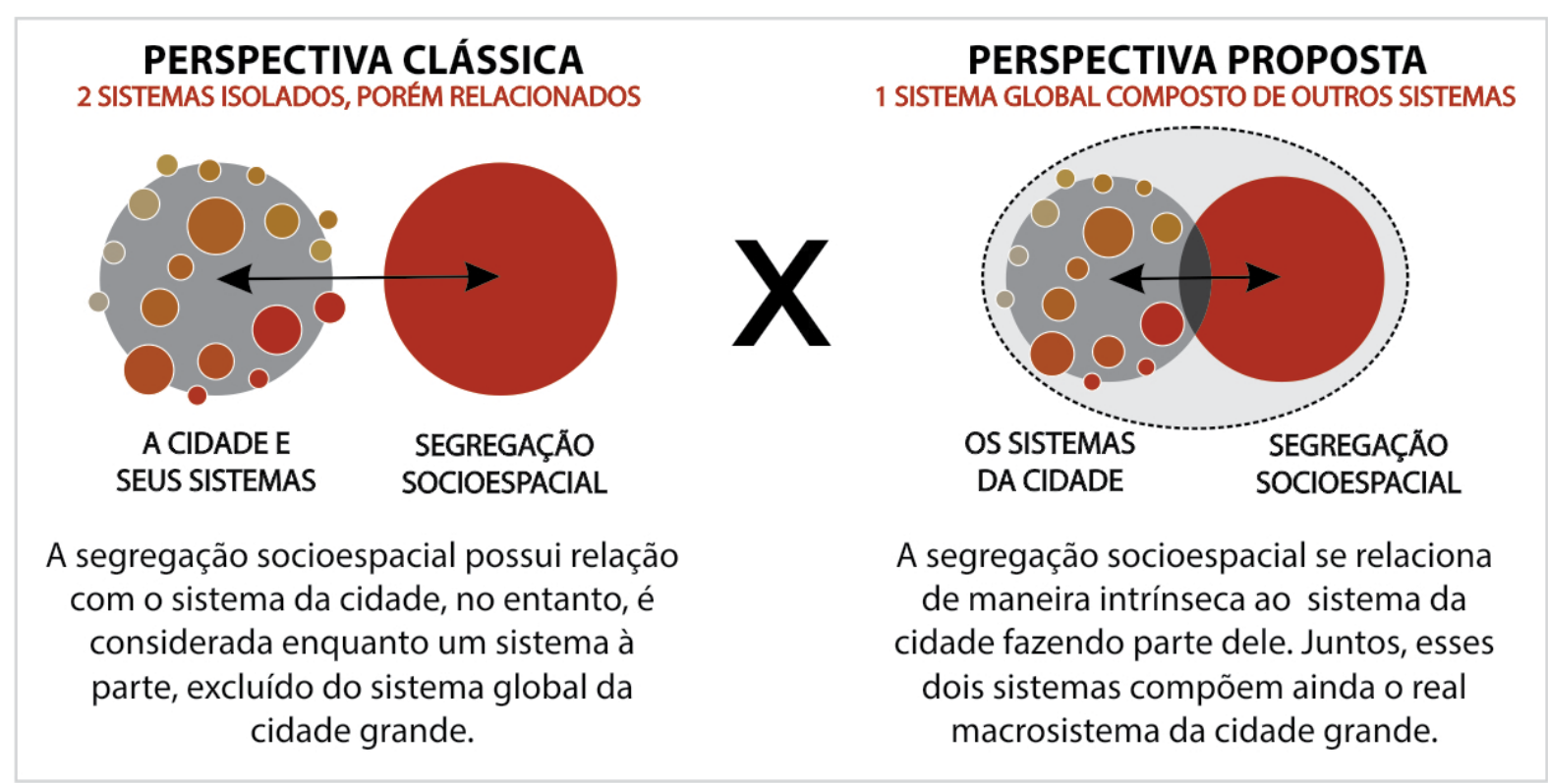

Figura 3. Diagrama da perspectiva clássica X Diagrama da perspectiva proposta na pesquisa. Fonte: Elaborado pelos autores. 
rísticas socioeconômicas. Segundo Litman (2015), uma cidade de tecido urbano disperso pode implicar na redução da acessibilidade, custos mais elevados para o fornecimento de infraestrutura e serviços públicos, distâncias maiores de viagens, mais congestionamento e poluição, assim como a redução de oportunidades sociais e econômicas.

É, portanto, nessa evolução do espaço urbano contemporâneo que uma nova estrutura urbana fragmentada se consolida e se relaciona, de maneira intrínseca, às formações e manutenções da segregação socioespacial nas metrópoles mundiais.

A origem do termo "segregação" conduz à percepção de uma separação de grupos sociais nas cidades por motivos diversos, sejam esses pela etnia, cultura, idade, classe econômica ou nacionalidade (COLL, 2012). No entanto, nas cidades de todo o mundo, têm-se a segregação urbana quase sempre relacionada com a divisão e luta de classes. É um processo imposto pelo capitalismo que revela as contradições econômicas e sociais da sociedade.

Coll $(2012$, p. 1) afirma que existem vários tipos de segregação, sendo o mais comum "aquela que acontece em decorrência da situação socioeconômica dos habitantes". Configura-se, portanto, a segregação enquanto consequência direta do instrumento de controle do capital nas cidades.
Harvey (2012) também discorre que o processo de segregação das cidades está ligado à estrutura social do capitalismo e que isso reflete, de maneira evidente, na reprodução espacial das cidades. O autor ressalta que a "gentrificação, a construção de condomínios fechados e a 'Disneyficação' do espaço" conformam ambientes degradantes para a maioria da população de baixa renda (HARVEY, 2012, p. 35).

Com isso, o capitalismo se torna um propulsor da segregação socioespacial presente na sociedade contemporânea, seja apartando as classes mais baixas ou, no caso dos condomínios fechados, isolando as classes dominantes. Partindo dessa dicotomia socioeconômica, se tornam muitas as possíveis classificação dos tipos de segregação urbana existentes. Lojikine (1997) classificou a segregação em três tipos: i) uma oposição entre o centro e a periferia; ii) uma separação acentuada entre as áreas ocupadas pelas classes mais populares e aquelas ocupadas pelas classes mais privilegiadas; iii) uma separação entre as funções urbanas, que ficam contidas em zonas destinadas a funções específicas (comercial, residencial, etc.)

Com esse breve panorama a respeito da segregação urbana, suas definições e classificações, torna-se possível, a partir de então, buscar compreender essa temática de maneira mais sistêmica, em uma tentativa de busca por soluções para esse problema incessante das cidades. 
Uma vez que a segregação urbana é composta por uma variedade de elementos que apresentem funções e comportamentos múltiplos, seus elementos estão em incessante evolução e possuem uma grande variedade de inter-relações; a segregação se insere adequadamente nas características de um "sistema", podendo assim, ser classificada e analisada como tal.

Mediante isso, têm-se aqui dois exemplos de análise da segregação socioespacial a partir da abordagem sistêmica. O primeiro exemplo é a metodologia de análise do espaço urbano dual das cidades desenvolvido por Milton Santos (2008) em "O espaço dividido: os dois circuitos da economia urbana dos países subdesenvolvidos". Baseado nas pesquisas de Neto e Leite (2010), o outro exemplo se trata de uma proposta empírica e metodológica da sistemografia aplicada à segregação socioespacial.

No primeiro exemplo, Santos (2008) utiliza uma teoria sistêmica para as cidades. Para o autor, a cidade não representa uma máquina maciça e é composta por dois sistemas da economia urbana denominados "circuito superior" e "circuito inferior". O primeiro representa os monopólios, relacionados às classes dominantes, enquanto o outro é formado de atividades econômicas de pequenas dimensões, de interesse à população pobre.
O autor relaciona esses circuitos de economia às configurações espaciais das cidades, visto que a influência do capitalismo é evidente para a segregação socioespacial. De certa forma, Santos (2008) demonstra que as cidades são, na realidade, um macrossistema formado por dois sistemas: um das classes mais baixas e outro das classes dominantes. Ressalta ainda que esse macrossistema funciona baseado em trocas de energia onde, à medida que as modernizações chegam, ocorrem trocas de energias entre os dois sistemas, onde um é dominante (circuito superior) e o outro é subordinado (circuito inferior). "A carga mais pesada da modernização é suportada pelos pobres, os que estão bem abaixo na escala dos salários (...)" (SANTOS, 2008, p. 193).

As análises sistêmicas urbanas realizadas por Santos (2008) levam a constatações importantes a respeito da segregação e pobreza urbana:

- “(...) a deformação do processo de desenvolvimento pela modernização (...) é responsável pela criação ou pela manutenção do que chamamos de circuito inferior da economia urbana" (SANTOS, 2008, p. 195-196).

- "(...) sem se levar em consideração esse circuito inferior, a compreensão da cidade é incompleta" (SANTOS, 2008, p. 196).

- "Os dois circuitos não são dois sistemas isolados e impermeáveis entre si, mas, ao contrário, estão em interação permanente" (SANTOS, 2008, p. 261). 
- "Esse círculo vicioso da pobreza é o resultado da superposição de dois mecanismos de espoliação, um mais econômico e o outro de natureza geográfica" (SANTOS, 2008, p. 371).

Neto e Leite (2010, p. 6) também utilizam a abordagem sistêmica enquanto método de análise para diversos parâmetros. Para eles, "a abordagem sistêmica pratica a interdisciplinaridade porque cria uma base conceitual comum que permite que desenvolvimentos (...) possam ser aplicados em outras áreas". Para empregar o paradigma sistêmico, os autores utilizam o método da sistemografia ${ }^{1}$ enquanto ferramenta, conformando uma metodologia em cinco etapas (Figura 4).

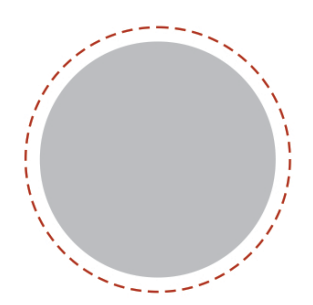

1) IDENTIFICAR O FENOMENO (REALIDADE)

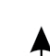

1. "O termo 'sistemografia' fo instituído por Le Moigne (1990) para designar a capacidade do sistema de agir como um jetos. A passagem da análise (reducionismo) à concepção (sistemografia) representa uma mudança nas finalidades do conhecimento. $\mathrm{Na}$ análise, é necessário explicar os componentes do objeto para conhecê-lo. Na concepção, é preciso conhecer e compreender o objeto para interpretá-lo e, assim, antecipar seu comportamento" (NETO e LEITE, 2010, p. 7).
A abordagem sistêmica é considerada enquanto um quadro de referência para a pesquisa. Dessa forma, ao realizar essa esquematização, é possível gerar diretrizes e orientações para futuras pesquisas no campo da segregação socioespacial. A intenção desse estudo é de caráter metodológico, com isso, não serão desenvolvidas as propostas práticas de análise de caso do fenômeno, visto que isso se configura enquanto assunto para outra pesquisa.

De maneira conseguinte, após a sistematização da metodologia em cada etapa, um fluxograma de síntese é elaborado visando a compreensão geral 


\begin{tabular}{|c|c|c|}
\hline \multicolumn{2}{|c|}{$\begin{array}{l}\text { PROPOSTA METODOLÓGICA DE } \\
\text { NETO E LETTE (2010) }\end{array}$} & $\begin{array}{c}\text { PROPOSTA APLICADA A } \\
\text { SEGREGAÇÄO SOCIOESPACIAL }\end{array}$ \\
\hline \multicolumn{2}{|r|}{ ETAPAS } & DIAGRAMAS TEMATICOS \\
\hline $\begin{array}{c}1^{\mathbf{3}} \\
\text { Identificar o } \\
\text { fenômeno }\end{array}$ & $\begin{array}{l}\text { Nesta etapa o pesquisador } \\
\text { deve definir o contexto de } \\
\text { pesquisa, identificar o objeto } \\
\text { ou fenômeno, os elementos } \\
\text { relacionados, o ambiente } \\
\text { imediato egeral e as fronteiras. }\end{array}$ & Movientos \\
\hline $\begin{array}{c}2^{\mathrm{s}} \\
\text { Desenvolver o } \\
\text { modelo geral }\end{array}$ & $\begin{array}{l}\text { O pesquisador constrói um } \\
\text { modelo geral que agrega todos } \\
\text { os conhecimentos acessiveis a } \\
\text { ele eque possam ser utilizados } \\
\text { para observar o fenómeno } \\
\text { identificado }\end{array}$ & UDADE \\
\hline $\begin{array}{c}3^{\mathrm{a}} \\
\text { Observar a } \\
\text { realidade por } \\
\text { isomorfismos }\end{array}$ & $\begin{array}{l}\text { O conhecimento agregado no } \\
\text { modelo geral passa a ser } \\
\text { utilizado para observar o } \\
\text { fenômeno real que está sendo } \\
\text { estudado. }\end{array}$ & $\begin{array}{l}\text { ACESSIBIIUDADE } \\
\text { URBANA }\end{array}$ \\
\hline $\begin{array}{l}4^{\mathrm{J}} \\
\text { Desenvolver } \\
\text { modelos da } \\
\text { realidade }\end{array}$ & $\begin{array}{l}\text { A realidade é representada por } \\
\text { modelos e/ou exemplos que } \\
\text { permitam torná-la mais } \\
\text { inteligível aos olhos do } \\
\text { pesquisador e da comunidade } \\
\text { em que estão inseridos. }\end{array}$ & \\
\hline $\begin{array}{l}5^{3} \\
\text { Agir sobre a } \\
\text { realidade }\end{array}$ & $\begin{array}{l}\text { O pesquisador irá agir sobre a } \\
\text { realidade com base no seu } \\
\text { modelo, de forma que ela se } \\
\text { aproxime dos seus objetivos de } \\
\text { pesquisa. }\end{array}$ & \\
\hline
\end{tabular}

Figura 5. Proposta metodológica de Abordagem Sistêmica aplicada à segregação socioespacial desenvolvida a partir de Neto e Leite (2010). Fonte: Elaborado pelos autores. de todo o sistema da segregação urbana (Figura 5).

A partir dessas etapas, se torna possível a elaboração um diagrama síntese de pesquisa sistêmica para a temática da segregação socioespacial (Figura 6). Para tal desenvolvimento, levou-se em consideração que a Teoria Geral do Sistemas pressupõe sempre a existência de um único macrossistema, o que conecta e relaciona todas as temáticas abordadas.

\section{Considerações Finais}

Em síntese, em meio às necessidades atuais de estudos mais abrangentes, o novo paradigma sistêmico surge orientando uma observação do "todo". No caso do urbanismo, esse "movimento de reorientação conceitual e metodológica" foi orientado para o estudo das cidades e suas relações com o sistema urbano, o que configurou uma compreensão desse sistema de forma dinâmica e complexa (IPEA, 2016).

Essa pesquisa foi o resultado de esforços para inserir a segregação socioespacial como categoria fundamental para a leitura e análise do espaço urbano. Visto que esse tema é comumente associado aos pré-conceitos de "exclusão" do sistema, esse estudo buscou e provou o contrário: a segregação não só é parte integrante do sistema das cidades como ainda é, de maneira autônoma, 
um amplo sistema formado por vários subsistemas importantes.

É importante ressaltar que a metodologia sistêmica realizada nesse estudo visa dar diretrizes e orientações para outras pesquisas no campo da segregação socioespacial. Conforme abordado anteriormente, a intenção desse estudo é de caráter metodológico, com isso, não foram desenvolvidas as propostas práticas de análise de caso do fenômeno, configurando-se enquanto assunto para futuras pesquisas.

No caso da proposta metodológica de abordagem sistêmica aplicada à segregação socioespacial, ressalta-se aqui que, nos diagramas elaborados foram definidos alguns temas relacionados à segregação, no entanto, ao proceder à aplicação dessa metodologia em um estudo de caso real, esses tópicos podem sofrer alterações e complementações conforme o contexto da cidade em análise.

Como visto, tanto o macrossistema das cidades quanto o sistema da segregação socioespacial estão envoltos em grossas camadas de complexidade. Talvez seja a existência dessa complexidade que torna o estudo desses assuntos tão pertinentes para a atualidade. É irrefutável admitir que as expansões urbanas se encontram em contínua

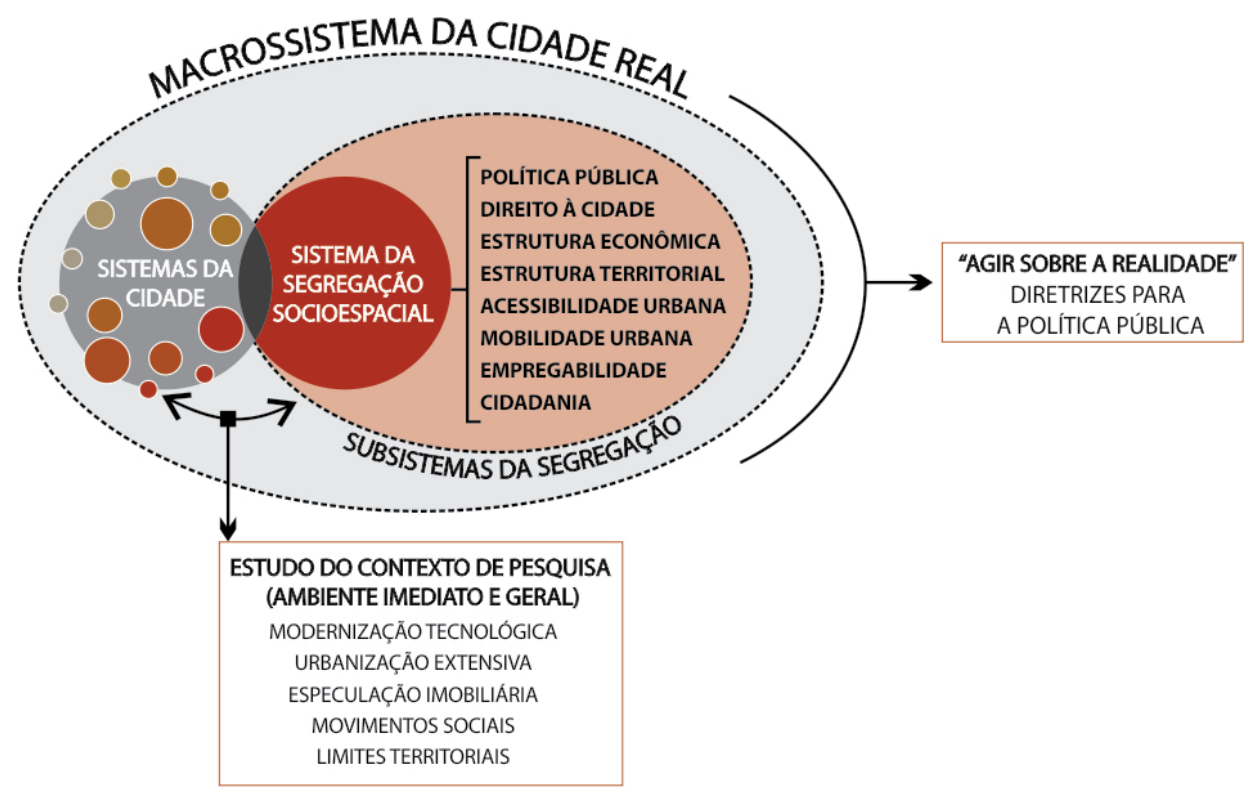

Figura 6. Diagrama síntese - proposta de pesquisa sistêmica orientada para a temática da segregação socioespacial Fonte: Elaborado pelos autores. 
evolução e que, de maneira desenfreada, suas consequências interferem diretamente na dinâmica da vida urbana, principalmente no que confere às discussões sobre a segregação socioespacial. Contudo, trazer uma perspectiva diferente - do tipo sistêmica - para abordar esse tema, expõe mais uma possibilidade de metodologia de análise da segregação. Uma vez que as cidades não podem ser vistas enquanto um bloco monolítico, mas como um todo multifacetado, compreender a segregação enquanto um sistema presente no macrossistema das cidades, oferece uma perspectiva mais próxima do que realmente ocorre na realidade.

\section{Referências:}

All Watched Over by Machines of Loving Grace. Direção: Adam Curtis. Produção: BBC Television. 3 episódios. 180min. 2011.

CANETTIERI, Thiago. A cidade capitalista na produção dos excluídos e os excluídos na produção da cidade capitalista: o paradoxo da exclusão urbana. Geoingá: Revista do Programa de Pós-Graduação em Geografia. v. 8. n. 1. p. 6483. 2015.

CEZARIO, Raquel Chaffin; CAETANO, Rodrigo da Costa. Metrópoles brasileiras: o reflexo da segregação sócio-espacial. In: III ENCONTRO DE GEOGRAFIA / VI SEMANA DE CIÊNCIAS HUMANAS.- 2010. Anais... Rio de Janeiro: Instituto Federal Fluminense, 2010, p.237-243.
COLL, Liana. Segregação social urbana: a serviço da manutenção da desigualdade. Revista Eletrônica O Viés: Junho, 2012. Disponível em: http://www.revistaovies.com/ cronicas/2012/06/ segregacao-social-urbana. Acesso em: juIho/2018.

DOMINGUEZ, Álvaro. (Sub)úrbios e (sub)urbanos - o mal estar da periferia ou a mistificação dos conceitos?. Revista da Faculdade de Letras Geografia. I Série, Vol. X/XI, Porto, 1994/5, p. 5-18.

DUARTE, Aldimar Jacinto. Jovens urbanos da periferia de Goiânia: espaços formativos e mediações escolares. 2012. Tese (Doutorado) - Faculdade de Educação, Universidade Federal de Goiás. 217p.

FERREIRA, Flávio. Apresentação à edição brasileira. In: LYNCH, Kevin. A imagem da cidade. Tradução de Jefferson Luiz Camargo. 3 ed. São Paulo: Editora WMF Martins Fontes, 2011.

GENTIL, C. D. A.; BEZERRA, M. C. L.; MEDEIROS, V. A. S. de. A forma urbana para a construção da mobilidade sustentável. Estudo de caso: Goiânia-GO. In: KNEIB, Erika Cristine (Org.). Projeto e cidade: mobilidade e acessibilidade em Goiânia. Goiânia: Editora UFG, 2016. p. 47-71.

HARVEY, D. Rebel cities: from the right to the city to the urban revolution. Londres: Verso, 2012. 
INSTITUTO DE PESQUISA ECONÔMICA APLICADA - IPEA. Cidade e movimento: mobilidades e interações no desenvolvimento urbano. Org.: BALBIM, Renato; KRAUSE, Cleandro; LINKE, Clarisse Cunha. Brasília: IPEA, ITDP, 2016. 326 p.

KASPER, Humberto. 0 processo de pensamento sistêmico: um estudo das principais abordagens a partir de um quadro de referência proposto. Dissertação de mestrado. 2000. 291p. Programa de Pós-graduação em Engenharia de Produção da Universidade Federal do Rio Grande do Sul. Porto Alegre.

LITMAN, Todd. Analysis of public policies that unintentionally encourage and subsidize urban sprawl. VTPI (Victoria Transport Policy Institute) e NCE (New Climate Economy). London: LSE Cities, mar. 2015.

LOJKINE, Jean. $O$ estado capitalista e a questão urbana. São Paulo: Martins Fontes, 1997.

MACEDO, Márcia Helena; SILVA, Antônio Nélson Rodrigues da; COSTA, Marcela da Silva. Abordagem sistêmica da mobilidade urbana: reflexões sobre o conceito e suas implicações. São Carlos: STT/CETEPE/EESC/USP, 2008.

MAIOLINO, Ana Lúcia Gonçalves; MANCEBO, Deise. Análise histórica da desigualdade: marginalidade, segregação e exclusão. Revista Psicologia \& Sociedade. $n^{\circ}$ 17. mai/ago. 2005. P. 14-20.
NEGRI, Silvio Moisés. Segregação Sócio-Espacial: Alguns Conceitos e Análises. Coletâneas do Nosso Tempo. ano VII. $n^{\circ}$ 8. 2008. p. 129-153.

NETO, Alfredo larozinski; LEITE, Maria Silene. A abordagem sistêmica na pesquisa em Engenharia de Produção. Revista Produção, v. 20, n. 1, p. 1-14. jan./mar. 2010.

OLIVEIRA, Josildete Pereira de; PORTELA, Lara Oliveira Viana. A cidade como um sistema: reflexões sobre a teoria geral de sistemas aplicada à análise urbana. Perspectivas Contemporâneas, Campo Mourão, v. 1, n. 2, p. 164-182, nov./maio 2006.

OJIMA, Ricardo. Dimensões da urbanização dispersa e proposta metodológica para estudos comparativos: uma abordagem socioespacial em aglomerações urbanas brasileiras. Revista Brasileira de Estudos de População. São Paulo, v. 24, n.2. p. 277-300, jul/dez. 2007.

ROMANELLI, Carla; ABIKO, Alex Kenya. Processo de Metropolização no Brasil. Texto Técnico da Escola Politécnica da USP. Departamento de Engenharia de Construção Civil. São Paulo: EPUSP, 2011. 34p.

SABOYA, Renato. Segregação espacial urbana. Urbanidades: maio, 2009. Disponível em: http://urbanidades.arq.br/2009/05/segregacao-espacial-urbana. Acesso em: julho/2018. 
SANTOS, Milton. O espaço dividido: os dois circuitos da economia urbana dos países subdesenvolvidos. 2 ed., 1. reimpr. São Paulo: Editora da Universidade de São Paulo, 2008.

SILVA, Geovany J. A. da. Cidades sustentáveis: uma nova condição urbana. Estudo de caso: Cuiabá-MT. 2011. 374 f. Tese de Doutorado. Programa de Pós-graduação em Arquitetura e Urbanismo - Universidade de Brasília. Brasília.
SILVA, Keli de Oliveira. A periferização causada pela desigual urbanização brasileira. Universidade Estadual de Maringá. Maringá - Paraná: Revista Urutágua. No 11 - Dez./Jan./Fev./ Mar.2007. p. 1-10

VILLAÇA, Flávio. Espaço intra-urbano no Brasil. 1 ed. São Paulo: Studio Nobel: FAPESP: Lincoln Institute, 2001. 373p. 